$110 / 60 \mathrm{mmHg}$ and pulse rate $130 / \mathrm{min}$ and regular. Results of laboratory investigations were normal. $S$. flexneri type 2a was later isolated from the stool. Treatment was started with ampicillin $250 \mathrm{mg}$ every 8 hours orally. Six hours after admission she had a grand mal seizure and shortly thereafter became apnoeic and unresponsive to noxious stimulation. The pupils were widely dilated $(6 \mathrm{~mm})$ and fixed, and there was no response to caloric or oculovestibular testing. Cerebrospinal fluid analysis was normal. Computerised tomography scan of the brain showed diffuse areas of low density throughout the brain. Five hours later the electroencephalogram was isoelectric. At necropsy the entire bowel was congested and the colonic mucosa was infiltrated by polymorphonuclear cells. Extensive necrosis was present throughout the brain and coning of the cerebellum was noted. The remainder of the organs seemed normal.

\section{Discussion}

Neurological complications of Shigella sp. infections are rare and consist of febrile convulsions in children and peripheral neuropathy in adults. ${ }^{3}$ Notable in the cases reported here were the lack of severe intestinal involvement and absence of metabolic derangement, and the fulminating nature of the encephalopathy. These facts suggest a toxic aetiology. $S$. flexneri type 2a may produce an exotoxin similar to that of $S$. dysenteriae type 1 . The toxin produced by the latter is a protein with a molecular weight of 50000 ; it is also a potent enterotoxin. It has the properties of a neurotoxin (being paralytic and lethal for rabbit and mouse) and cytotoxic (lethal for cell culture) in addition to causing intestinal fluid secretion. ${ }^{3}$ Although the exact role of this substance in the pathogenicity of shigellae remains undefined, we suggest that such a toxin, either elaborated in the gut or ingested preformed, was responsible for the rapidly fatal picture described in these 3 patients. The precise mechanism of action on the nervous system is unknown, since no specific disease was revealed in the brains at necropsy. In all 3 patients, areas of necrosis were present throughout the brains; only in Case 1 were pontine haemorrhages and demyelination seen. Haemorrhages may be explicable on the basis of raised intracranial pressure before death, while the demyelination may reflect an action of the toxin or be an incidental finding. This report supports the evidence of a particular neurotoxic effect in shigellosis.

\section{References}

1 Kowlessar M, Forbes G B. The febrile convulsion in shigellosis. N Engl J Med 1966; 258: 520-6.

2 Donald W D, Winkler C H, Jr, Bargeron L M, Jr. The occurrence of convulsions in children with shigella gastroenteritis. J Pediatr 1956; 48: 323-7.

3 Smith D H. Shigellosis (bacillary dysentery). In: Vaughan V C, McKay R, Jr, Behrman R E, eds. Nelson textbook of pediatrics, eleventh edition. Philadelphia: Saunders, 1979: 782-6.

Correspondence to $\operatorname{Dr} R$ Sandyk, University of the Witwatersrand, Medical School, Hospital Street, Johannesburg 2001, South Africa.

Received 11 September 1982

\title{
Influence of breast feeding on the clinical features of salt-losing congenital adrenal hyperplasia
}

\section{JOSEPH A CURTIS AND JOHN D BAILEY}

Division of Endocrinology, Department of Pediatrics, Hospital for Sick Children, Toronto, Canada

SUMMARY Feeding habits before diagnosis were reviewed in 32 infants with salt-losing congenital adrenal hyperplasia who were admitted to hospital in adrenal crisis. Most breast-fed babies failed to thrive, seldom vomited, and despite severe salt wasting, presented at a later age than their formulafed counterparts.

Salt-losing congenital adrenal hyperplasia (SL-CAH) is a genetically inherited enzyme deficiency, the most commonly affected enzyme being 21-hydroxylase. ${ }^{1}$
Clinically, SL-CAH is characterised by a nonspecific failure to thrive in the first few days of life that progresses to acute addisonian crisis with anorexia, vomiting, dehydration, dystrophy, diarrhoea, and circulatory insufficiency in the 2nd week. ${ }^{2}$

Although the initial crisis occurs in most infants with SL-CAH in the 2nd or 3rd weeks of life, it can occur as early as the first week or as late as several months. Kowarski ${ }^{3}$ suggests that the age at which the infant presents depends on the severity of the case, which in turn is related to the degree of sodium 
Table Presenting features in 32 infants with salt-losing congenital adrenal hyperplasia

\begin{tabular}{|c|c|c|c|c|c|c|c|}
\hline Method of feeding & $\begin{array}{l}\text { Number of } \\
\text { patients }\end{array}$ & $\begin{array}{l}\text { Age at } \\
\text { presentation } \\
\text { (days) }\end{array}$ & $\begin{array}{l}\text { Failure } \\
\text { to } \\
\text { thrive }\end{array}$ & Vomiting & $\begin{array}{l}\text { Daily } \\
\text { weight } \\
\text { losst } \\
(\%)\end{array}$ & $\begin{array}{l}\text { Plasma } \\
\text { sodium } \\
(\text { mmol } / \text { l) }\end{array}$ & $\begin{array}{l}\text { Number with } \\
\text { severe salt } \\
\text { depletion } \div\end{array}$ \\
\hline Breast & 8 & $\begin{array}{l}31 \\
(14-44)\end{array}$ & 7 & 1 & $0 \cdot 34$ & $\begin{array}{l}110 \\
(93-125)\end{array}$ & 4 \\
\hline Breast and formula & 5 & $\begin{array}{l}33 \\
(10-77)\end{array}$ & 3 & 2 & 0.46 & $\begin{array}{l}118 \\
(97-126)\end{array}$ & 1 \\
\hline Formula & 19 & $\begin{array}{l}17 * \\
(5-56)\end{array}$ & 5 & 14 & 0.95 & $\begin{array}{l}119 \\
(97-132)\end{array}$ & 3 \\
\hline
\end{tabular}

*P value $<0.05$, Duncan's analysis of variance. †Calculated as a percentage of birthweight lost per day. $\ddagger P l a s m a ~ s o d i u m ~<110$ mmol/1.

depletion. Salt loss would thus be fairly mild in infants who present after the 3rd week of life.

The diagnosis of SL-CAH in a 39-day-old, breast-fed infant who presented with failure to thrive without vomiting and had a plasma sodium concentration of $108 \mathrm{mmol} / \mathrm{l}$ led us to examine whether the method of feeding newborn infants with SL-CAH influenced the age and characteristics of the clinical presentation.

\section{Patients and methods}

The medical records of all patients with SL-CAH seen at our hospital from 1953 to 1980 were studied for details of feeding before diagnosis, age at presentation, and presenting symptoms. If the history was incomplete, the data were checked with the infant's mother, family practitioner, and paediatrician. Altogether 50 cases were identified, the diagnosis in each being confirmed by measurement of urinary ketosteroids and pregnanetriol, and, more recently, of plasma 17-hydroxyprogesterone.

Thirty-two of these infants ( 23 boys, 9 girls) were discharged from hospital shortly after birth, undiagnosed and apparently healthy, and were readmitted only when they were in adrenal crisis. Eight had been breast fed, 5 were fed breast milk and formula consecutively, and 19 were fed with formula alone. The remaining 18 infants ( 1 boy, 17 girls) had been noted at birth to have features suggestive of CAH, but were omitted from the study because they had been detained in hospital for observation and further investigations.

\section{Results}

The clinical features of the breast-fed and formulafed infants are given in the Table.

The differences in age at presentation between the formula-fed infants and those who were either totally or partially breast fed were significant $(\mathrm{P}<0 \cdot 05)$.
Because of continuing failure to thrive, formula $\stackrel{0}{\circ}$ feeds were briefly tried in 6 of the entirely breast-fed infants. This however, precipitated vomiting in all $\searrow$ cases, and the formula was quickly stopped. 을 Although 4 of the babies reverted to breast feeding without further incident, the condition of the other 2 deteriorated rapidly and they became shocked within 48 hours, because of repeated vomiting in one infant and refusal of breast milk in the other.

\section{Discussion}

In infants with SL-CAH the clinical features typically reflect the severity of salt depletion, which is governed by the level of aldosterone in the body. Since aldosterone clearance is slow in newborn infants, adequate concentration of the hormone is maintained even if the secretion rate is low. However, in the 2nd week of life aldosterone clearance increases, due to maturation of hepatic enzyme pathways, and increased secretion is necessary. In SL-CAH, aldosterone secretion occurs in inverse proportion to the severity of the 21-hydroxylase defect. ${ }^{4}$ Thus, presentation tends to be early in severe salt-losers, and is later in milder cases in whom the aldosterone level remains adequate for a longer time. However, as this study has shown, the severity of salt depletion does not always dictate the age at presentation, most of the breast-fed babies presenting late despite severe salt wasting. This may be surprising since most of the formula used during the period of the study $N$ contained a far higher sodium content than either modern formula feeds or breast milk.

While breast-fed infants with SL-CAH have all $\underset{\omega}{\mathcal{C}}$ the biochemical features of adrenal insufficiency at $\underset{2}{ }$ an early age, they do not show the clinical picture of 0 the classical adrenal crisis because the salt depletion $\mathbb{D}$ is not complicated by the severe water loss that ? results from vomiting. Thus, they are not recognised 0 as having a serious metabolic disorder, their weight loss being ascribed to insufficiency of breast milk. Weaning, which is known to precipitate vomiting 
even in healthy infants, ${ }^{5}$ unmasks the true nature of the underlying disorder in many such infants who, already profoundly salt-depleted and unable to tolerate further fluid loss, sink rapidly into severe dehydration and shock. The aldosterone content of breast milk is unknown, but it may, as in the case of progesterone, reflect blood concentration. ${ }^{6}$ The possibility that this or other breast milk steroids might exert a therapeutic effect on breast-fed infants with SL-CAH cannot be excluded, but given the profound salt wasting present in these infants, the plasma concentration of such hormones after absorption from the gastrointestinal tract would seem to be insufficient to influence renal sodium conservation. diagnosis of failure to thrive at the breast, and plasma electrolytes determined before the introduction of formula which may precipitate vomiting. For this reason, although breast feeding should always be encouraged, it is particularly desirable in babies with suspected SL-CAH while the results of confirmatory diagnostic tests are awaited and treatment is begun.

We thank Dr M M Wood, HSC, for statistical analysis, and Miss C Conway for typing the manuscript.
SL-CAH should be included in the differential

hydroxyprogesterone was developed at HSC by $\mathrm{Dr}$ Graham Ellis, using an antibody (type $M$ 156) which was obtained from Professor W R Butt, Birmingham and Midland Hospital for Women.

\section{References}

1 Bongiovanni A M, Root A W. The adrenogenital syndrome. $N$ Engl J Med 1963; 268: 1283-9.

2 Zurbrugg R P. Congenital adrenal hyperplasia. In: Gardner L I, ed. Endocrine and genetic diseases of childhood and adolescence, second edition. Philadelphia: Saunders, 1975: 476-500.

3 Kowarski A A. Mechanism of salt loss in congenital virilizing adrenal hyperplasia. In: Lee $\mathbf{P}$ A, Plotnick L P, Kowarski A A, Migeon C J, eds. Congenital adrenal hyperplasia. Baltimore: University Park Press, 1977: 113-24.

4 Kowarski A, Finkelstein J W, Spaulding J S, Holman G H, Migeon C J. Aldosterone secretion rate in congenital adrenal hyperplasia. A discussion of the theories on the pathogenesis of the salt-losing form of the syndrome. $J$ Clin Invest 1965; 44: 1505-13.

5 Cussen V G H. Breast feeding and neonatal morbidity. In: Wharton B A, ed. Topics in perinatal medicine. Tunbridge Wells: Pitman Medical, 1980: 79-87.

6 Darling J A B, Laing A H, Harkness R A. A survey of the steroids in cows' milk. J Endocrinol 1974; 62: 291-7.

Correspondence to Dr A Curtis, Department of Paediatrics, The Regional Hospital, Wilton, Cork, Ireland.

The radioimmunoassay method for plasma 17- Received 1 September 1982

\section{Supplementary water for breast-fed babies in a hot and dry climate--not really a necessity}

\section{N M GOLDBERG AND E ADAMS}

Department of Paediatrics, Joseftal Medical Centre, Eilat, Israel

SUMMARY Urine osmolarity under hot and dry climatic conditions remains within the expected physiological ranges and thus shows that supplementary water for breast-fed infants is not necessary.

It is generally agreed that infants in a hot and dry climate need extra water. This assumption was based more on caution than on knowledge. ${ }^{1}$ Recently breast-fed infants in a hot and humid climate were found to do well without supplementary water. ${ }^{2} 3$

A field study was undertaken in two bedouin villages on the coastal side of the Sinai desert during the summer to find out the fluid requirement of totally breast-fed infants in a hot and dry climate.

\section{Materials and methods}

Fifteen healthy exclusively breast-fed infants ( 9 boys, 6 girls) were studied. They were aged between 40 and 150 days.

Urine was collected using adhesive collector bags. The samples were taken either after 1000 hours or before 1600 hours. Urine was then frozen and analysed within 24 hours using the Fiske osmometer (Fiske Associates, Burlington, Mass. 01803).

Temperature and humidity readings for the duration of the study were provided by the Israeli Meteorological Service.

\section{Results}

Urine osmolarity measurements are shown in the 